\title{
Increased hypothalamic serotonin turnover in inflammation-induced anorexia
}

\author{
J. T. Dwarkasing ${ }^{1 *}$, R. F. Witkamp ${ }^{1}$, M. V. Boekschoten², M. C. Ter Laak ${ }^{1}$ M. S. Heins ${ }^{3}$ and K. van Norren ${ }^{1}$
}

\begin{abstract}
Background: Anorexia can occur as a serious complication of disease. Increasing evidence suggests that inflammation plays a major role, along with a hypothalamic dysregulation characterized by locally elevated serotonin levels. The present study was undertaken to further explore the connections between peripheral inflammation, anorexia and hypothalamic serotonin metabolism and signaling pathways. First, we investigated the response of two hypothalamic neuronal cell lines to TNFa, IL- 6 and LPS. Next, we studied transcriptomic changes and serotonergic activity in the hypothalamus of mice after intraperitoneal injection with TNFa, IL-6 or a combination of TNFa and IL-6.

Results: In vitro, we showed that hypothalamic neurons responded to inflammatory mediators by releasing cytokines. This inflammatory response was associated with an increased serotonin release. Mice injected with TNFa and IL-6 showed decreased food intake, associated with altered expression of inflammation-related genes in the hypothalamus. In addition, hypothalamic serotonin turnover showed to be elevated in treated mice.
\end{abstract}

Conclusions: Overall, our results underline that peripheral inflammation reaches the hypothalamus where it affects hypothalamic serotoninergic metabolism. These hypothalamic changes in serotonin pathways are associated with decreased food intake, providing evidence for a role of serotonin in inflammation-induced anorexia.

\section{Background}

Loss of appetite (anorexia) leading to insufficient food intake is often seen in chronic illnesses including cancer, HIV and COPD. A chronically elevated increased inflammatory tone is considered one of the major drivers of anorexia in these diseases. Studies suggest that an ongoing elevated inflammatory tone in the hypothalamus, displaying the highest density of various cytokine receptors in the brain [1], is implicated in these disturbances in food intake. Inflammatory mediators affect important orexigenic and anorexigenic regulators including NPY [2] and POMC [3, 4] peptides in the hypothalamus. Cytokines and other pro-inflammatory signalling molecules from the periphery are able to reach the hypothalamus passing the blood brain barrier (BBB) [5-7]. In addition, de novo synthesis of various cytokines in the hypothalamus has been reported [8]. To trigger these

\footnotetext{
*Correspondence: jvalini@hotmail.com

${ }^{1}$ Nutrition and Pharmacology Group, Division of Human Nutrition,

Wageningen University, Bomenweg 2,6703HD Wageningen, The Netherlands

Full list of author information is available at the end of the article
}

processes, sensing of peripheral signals in the adjacent median eminence $[9,10]$ and activation of hypothalamic microglial and astrocyte cells $[11,12]$ might be crucial.

We previously described changes in hypothalamic serotonin signalling in rodent tumour models displaying severe body wasting (cachexia). These changes in serotonin formation were inversely associated with food intake [13]. This is in line with findings in a variety of chronic illnesses, where increased hypothalamic serotonin has been implicated for its role in the development of disease-associated anorexia [14-17]. Hypothalamic serotonin plays an important role in food intake, since it is able to respond to peripheral signals on energy status [18-20] and it is able to modulate anorexigenic and orexigenic signalling in the hypothalamus. Serotonin is able to affect food intake via activation of the anorexigenic melanocortin system involving 5HT2c receptors [21] and by inhibition of the orexigenic NPYergic system [15, 22]. Furthermore, reduction of brain serotonin by reducing availability of its precursor tryptophan (TRP) (Fig. 1) has been shown to be beneficial in the treatment in anorexia during cancer [23]. 


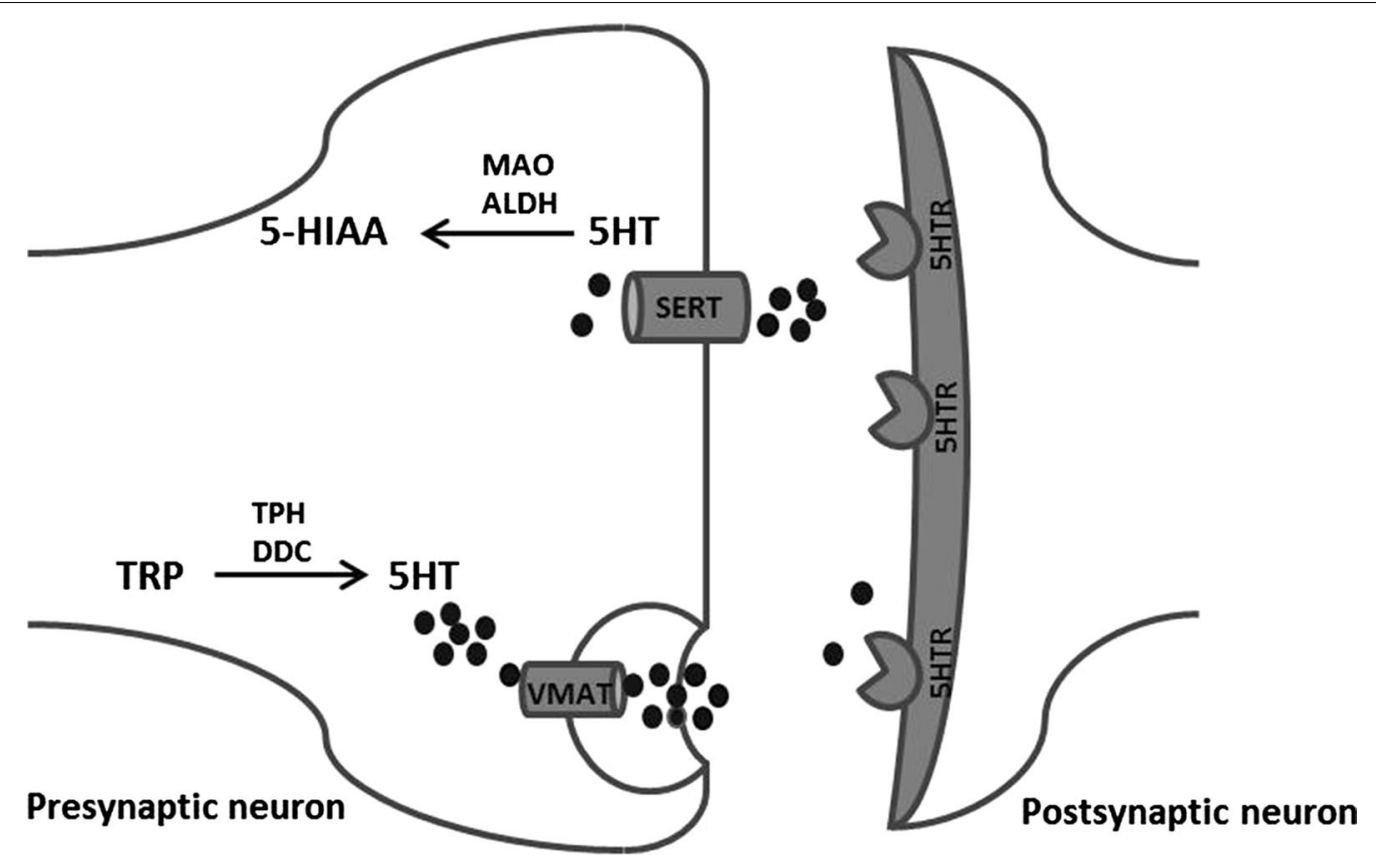

Fig. 1 Serotonergic transmission in neurons. Conversion of tryptophan (TRP) to serotonin (5HT) is catalysed by TPH and DDC. Serotonin is then, by transportation via VMAT, stored into vesicles before it can be released into the synaptic cleft. There, serotonin signalling resulting from binding to serotonin receptors (5HTR) can be terminated by the reuptake of serotonin via SERT transporter. Once serotonin is taken up into the presynaptic neuron it is degraded by MAO and ALDH to 5-HIAA, which is considered a marker for serotonergic activity and measurable for a longer period compared to levels of secreted serotonin. TRP tryptophan, TPH tryptophan hydroxylase, 5-HT serotonin, 5HTR serotonin receptor, 5-HIAA 5 hydroxyindolacetic acid, DDC dopadecarboxylase, VMAT vesicular monoamine transporter, SERT serotonin reuptake transporter, MAO monoamine oxidase, ALDH aldehyde dehydrogenase

In the present study, we investigated the anorexigenic effects of TNF $\alpha$ and IL-6, cytokines that are often elevated during chronic illness, on hypothalamic serotonin signalling. To test physiologically relevant concentrations of TNF $\alpha$ and IL- 6 in illness, we included two combinations containing both TNF $\alpha$ and IL- 6 that reflected plasma levels measured in C26 adenocarcinoma tumourbearing mice or Lewis Lung tumour-bearing mice respectively [13, 24]. We show that these cytokines when administered intraperitoneally (ip) induce changes in the hypothalamic transcriptome consistent with changes in inflammatory pathways and serotonin signalling. Furthermore, these cytokines alter hypothalamic levels of serotonin's main metabolite 5-HIAA (Fig. 1), indicating that synaptic serotonin release $[25,26]$ and serotonin turnover $[27,28]$ is affected by inflammation.

\section{Results}

IL-6, TNFa and LPS increase inflammatory markers, 5HT and 5-HIAA in hypothalamic cell lines

Exposure of hypothalamic cell lines hypoE-46 and hypoA2/12 to IL-6 (100 pg/ml), TNF $\alpha(100 \mathrm{pg} / \mathrm{ml})$ and LPS $(1 \mu \mathrm{g} / \mathrm{ml})$ for $24 \mathrm{~h}$ stimulated serotonin $(5 \mathrm{HT})$ release into the medium. Furthermore, levels of intracellular 5-hydroxyindoleacetic acid (5-HIAA) were elevated after exposure to IL-6, TNF $\alpha$ and LPS in both cell lines. Both cell lines produced IL- 6 when exposed to IL- 6 , since levels detected were four to sixfold higher than exposed levels. In addition, both cell lines produced MCP-1 when exposed to LPS and IL- 6 . Compared to IL- 6 and LPS, TNF $\alpha$ showed to be less potent in inducing the production of MCP-1 and IL-6 (Fig. 2). No TNF $\alpha$ release was detected (data not shown) after exposure to IL-6, TNF $\alpha$ or LPS.

\section{IL-6 and TNFa reduce food intake in mice}

Hourly food intake remained constant in control animals during the entire study period. In cytokine treated mice, food intake curves started to deviate from $2 \mathrm{~h}$ after injection, becoming significantly lower $4 \mathrm{~h}$ after injection in the TNF $\alpha$, IL-6 high, IL-6 Low + TNF $\alpha$ and IL-6 High + TNFa groups, compared to controls (Fig. 3). These effects did not differ between cytokine treatments. After $5 \mathrm{~h}$ of injection, food intake between all groups was similar again.

Plasma levels of cytokines and serum amyloid A levels in liver were measured $5 \mathrm{~h}$ after injection. There were three groups with significant changes in plasma TNF $\alpha$, 


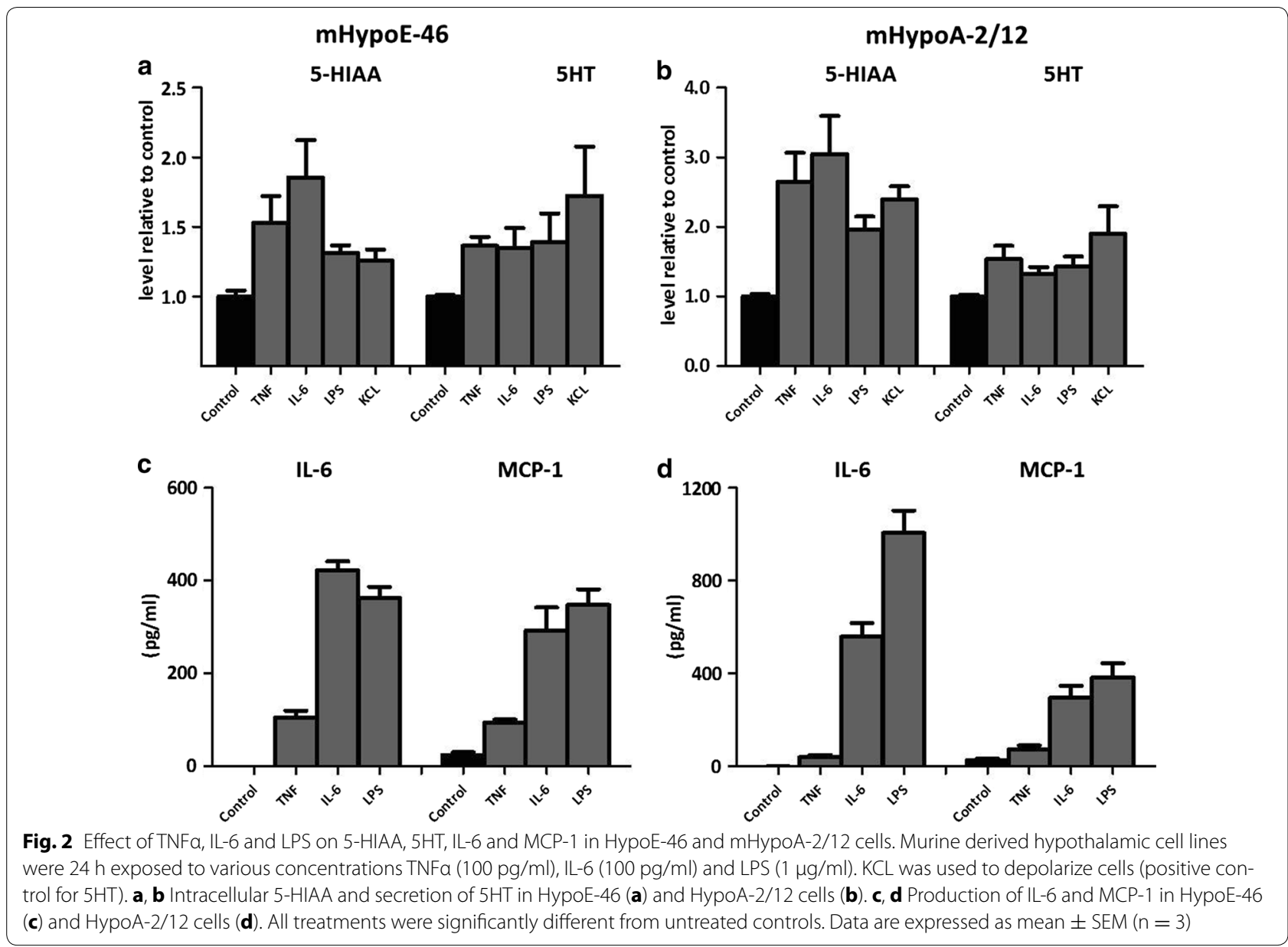

IL-6 or liver SAA levels: the two combination groups and the IL-6 high group. Plasma IL-6 was significantly higher in the two combination groups, while TNF $\alpha$ was increased in the IL-6 high and the TNF + IL-6 Low group. The elevation of the other combination group did not reach significance. Liver SAA was only significantly increased in the IL-6 high group (Fig. 3). Plasma levels of MCP-1, leptin, resistin, PYY, amylin, GIP, GLP-1 and insulin were not different between groups (Additional file 1: Figure 1). Ghrelin, pancreatic peptide and glucagon plasma levels were below detection limit of the assay.

\section{IL-6 and TNFa increase hypothalamic 5-HIAA and TRP}

Total hypothalamic serotonin (5HT) tissue concentrations were not affected by injection with TNF and/or IL-6 $5 \mathrm{~h}$ after injection. However, serotonin's metabolite, 5-hydroxyindoleacetic acid (5HIAA), showed to be significantly elevated in hypothalamus homogenates of both the TNF + IL-6 Low and TNF + IL-6 High groups compared to controls (Fig. 4). These increases were more prominent than those following injection with TNF, IL-6 Low and IL-6 High alone. Tryptophan (TRP) showed to be significantly higher in mice injected with TNF + IL-6 High compared to controls. Hypothalamic levels of dopamine (DA) and its metabolite 3,4-dihydroxyphenylacetic acid (DOPAC) showed no differences between groups (Fig. 4).

\section{Hypothalamic transcriptome analysis: IL- 6 and TNFa have similar effects on serotonin signalling and inflammatory pathways}

Expression of genes that were changed with a fold change greater than 1.5 compared to controls were compared among the different groups, resulting in a list of 118 genes (Figs. 5, 6, 7). From these genes, 87 genes showed to be altered in a similar direction (either up or down compared to controls) in at least 4 out of 5 treatment groups. Furthermore, 96 out of 118 genes were overlapping between animals from the TNF and IL-6 Low or IL-6 High groups. Altogether this shows that induced changes on gene expression were overall similar for treatment with TNF, IL-6 or the combination. More importantly, gene expression of rate-limiting enzymes involved in the synthesis of 5HT, including Tph2 and expression 

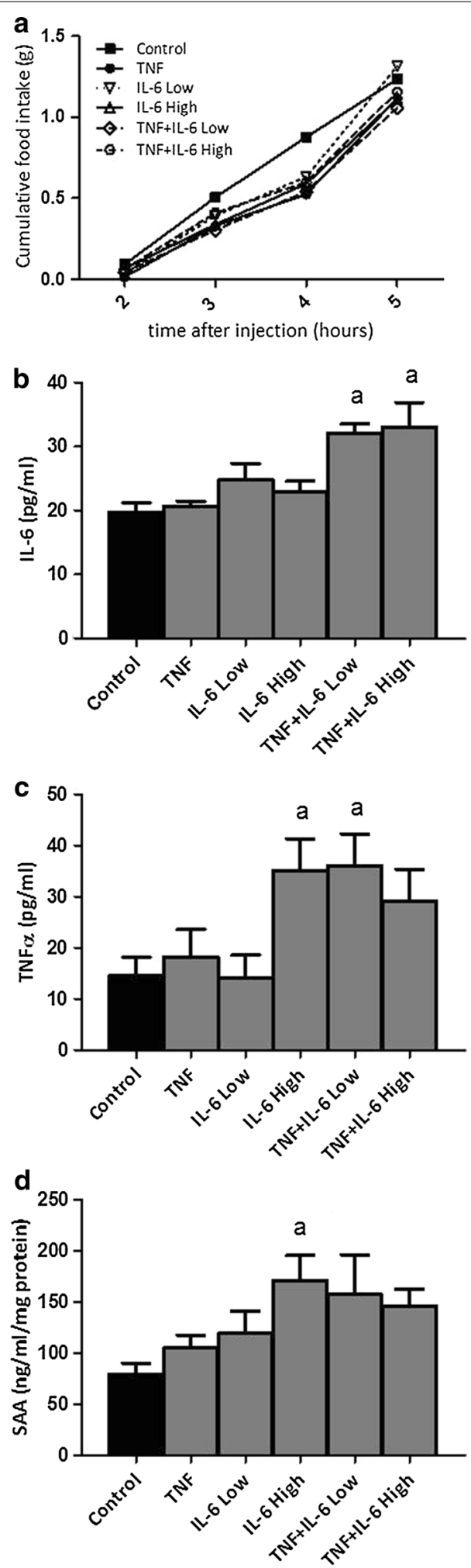

Fig. 3 Effect of injection with TNFa, IL-6 or both on food intake and plasma cytokines. a Time course of food intake after injection with TNFa, IL-6 or both. b, c IL-6 and TNFa plasma levels $5 \mathrm{~h}$ after injection. $\mathbf{d}$ Level of serum amyloid 1 (SAA) in liver homogenates $5 \mathrm{~h}$ after

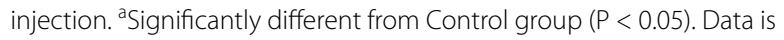
expressed as mean $\pm \operatorname{SEM}(n=12)$

of the serotonin-reuptake transporter, Slc6a4, were found to be among these highly upregulated genes. Strongly down-regulated genes included those of two important orexigenic regulators NPY and AgRP. Treatment effects showed to be similar for NPY and AgRP and these were most prominent in the IL-6 Low and TNF $\alpha+$ IL-6 Low groups (Figs. 5, 6, 7). Using Ingenuity, upstream regulators that were present in at least 3 treatment groups were listed (Table 1). Overall, this revealed an inflammatory profile of upstream regulators, which included cytokines IFN $\gamma$, TGF $\beta$ and IL- 6 and the enzyme IKBKG which is an encoded protein of the IKB complex, and crucial for activating NFKB. The Ingenuity database used included 75 IFNY target genes of which 19 out of 27 had an overlap with IL-6 target genes, which might explain the mutual presence of both these cytokines.

\section{Discussion}

Decreased food intake (anorexia) often occurs during conditions characterized by an elevated inflammatory response. In this study we investigated the role of serotonin in this decreased food intake during inflammation. Here, we show that both in vitro and in vivo hypothalamic inflammation is associated with increased serotonergic activity. Overall supporting the viewpoint that changes in hypothalamic 5HT signaling are involved in anorexia resulting from inflammation.

Interestingly, we found that the two hypothalamic cell lines used here (HypoE-46 and HypoA-2/12), which are derived from different neuronal populations of the hypothalamus, the PVN [29] and the ARC [30] respectively, are able to produce inflammatory mediators when exposed to LPS, TNF $\alpha$ or IL-6. Upon exposure to IL-6 and TNF $\alpha$, neurons responded by the production of IL- 6 and MCP-1, but not TNFa. MCP-1 production is regulated by IL-6, suggesting that MCP-1 production upon exposure to TNF might also involve the production of IL-6 [31].

So far, studies on hypothalamic inflammation have primarily focussed on the role of microglial and astrocyte activation [11, 12, 32, 33]. However, it has been shown 

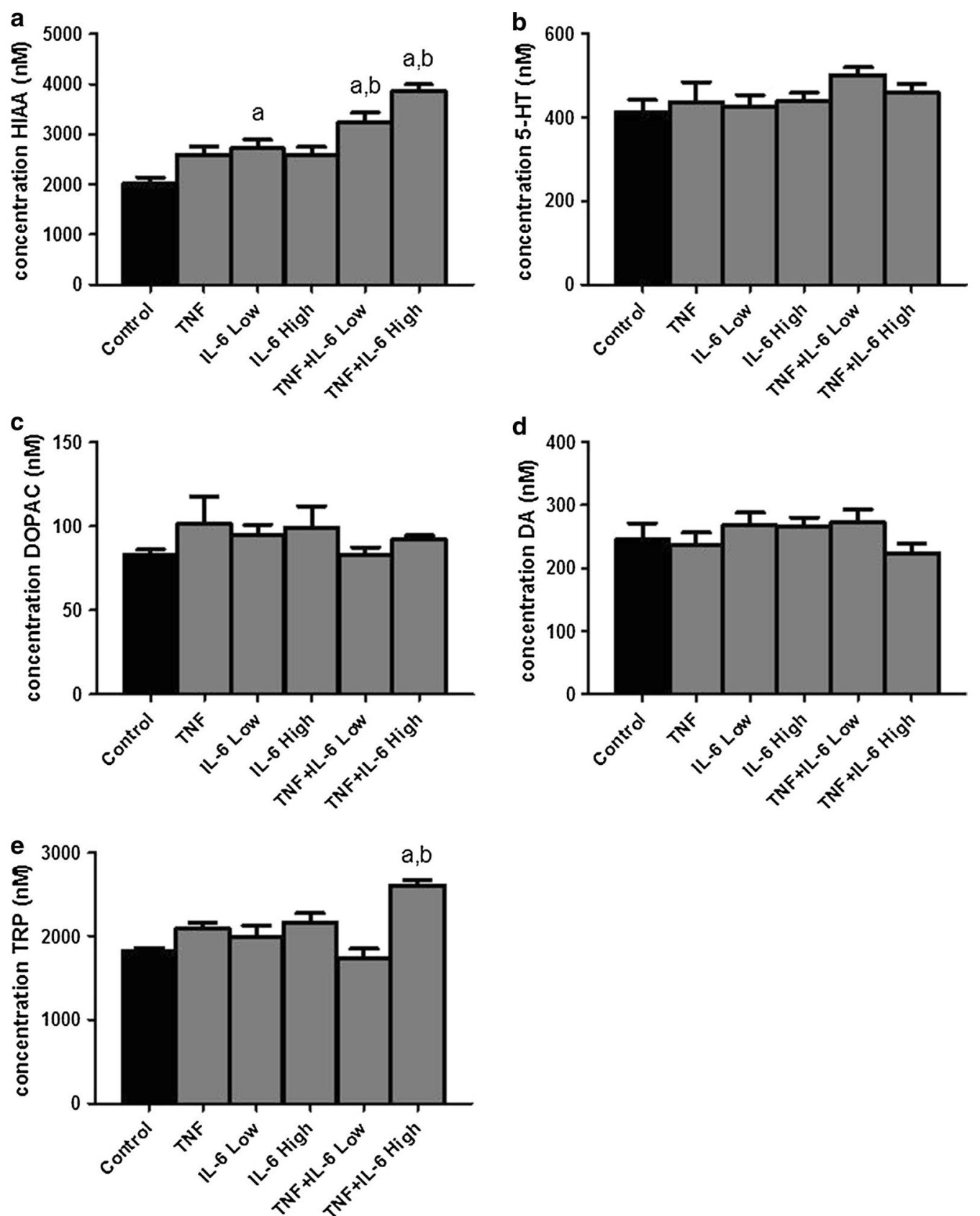

Fig. 4 Levels of tryptophan, serotonin and dopamine and their metabolites in the hypothalamus. Effect of ip injection with TNFa, IL-6 or both on a 5-hydroxyindoleacetic acid (5HIAA), b Serotonin (5HT), c 3,4-dihydroxyphenylacetic acid (DOPAC), d Dopamine (DA) and e tryptophan (TRP). asignificantly different from Control group $(P<0.05)$, ${ }^{b}$ significantly different from TNF, IL-6 Low and IL-6 High group $(P<0.05)$. Data is expressed as mean $\pm \operatorname{SEM}(n=6)$

Fig. 5 Gene expression changes in hypothalamus after ip injection with TNFa, IL-6 or both. Top upregulated genes and top downregulated genes in treated groups compared to control group. Each row represents a gene and each column represents a group of animals. Magenta colour indicates genes that were higher expressed as control and green colour indicates genes that were lower expressed as the control. Black indicates genes whose expression was similar to compared to control. ID: Entrez ID 


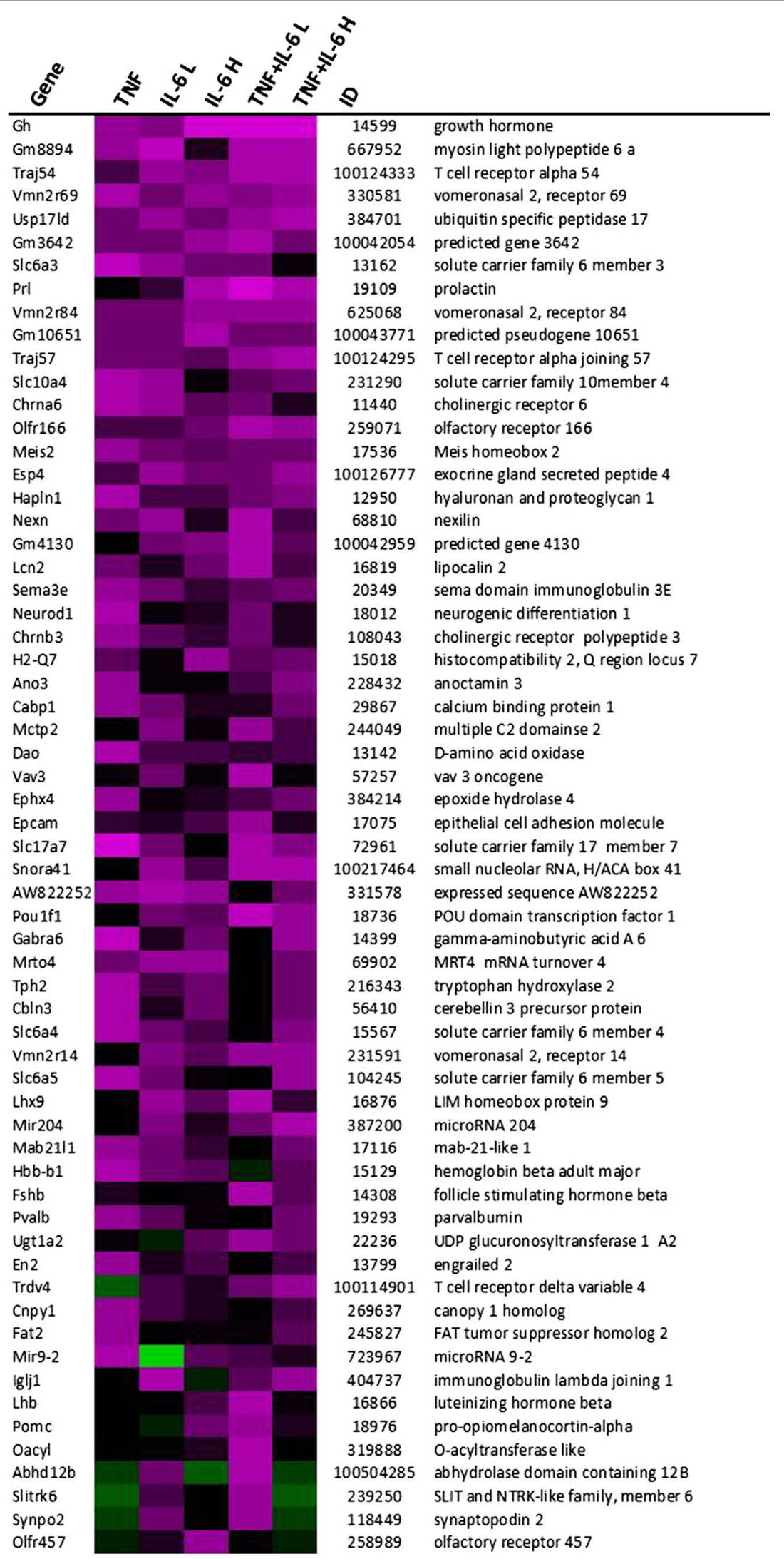




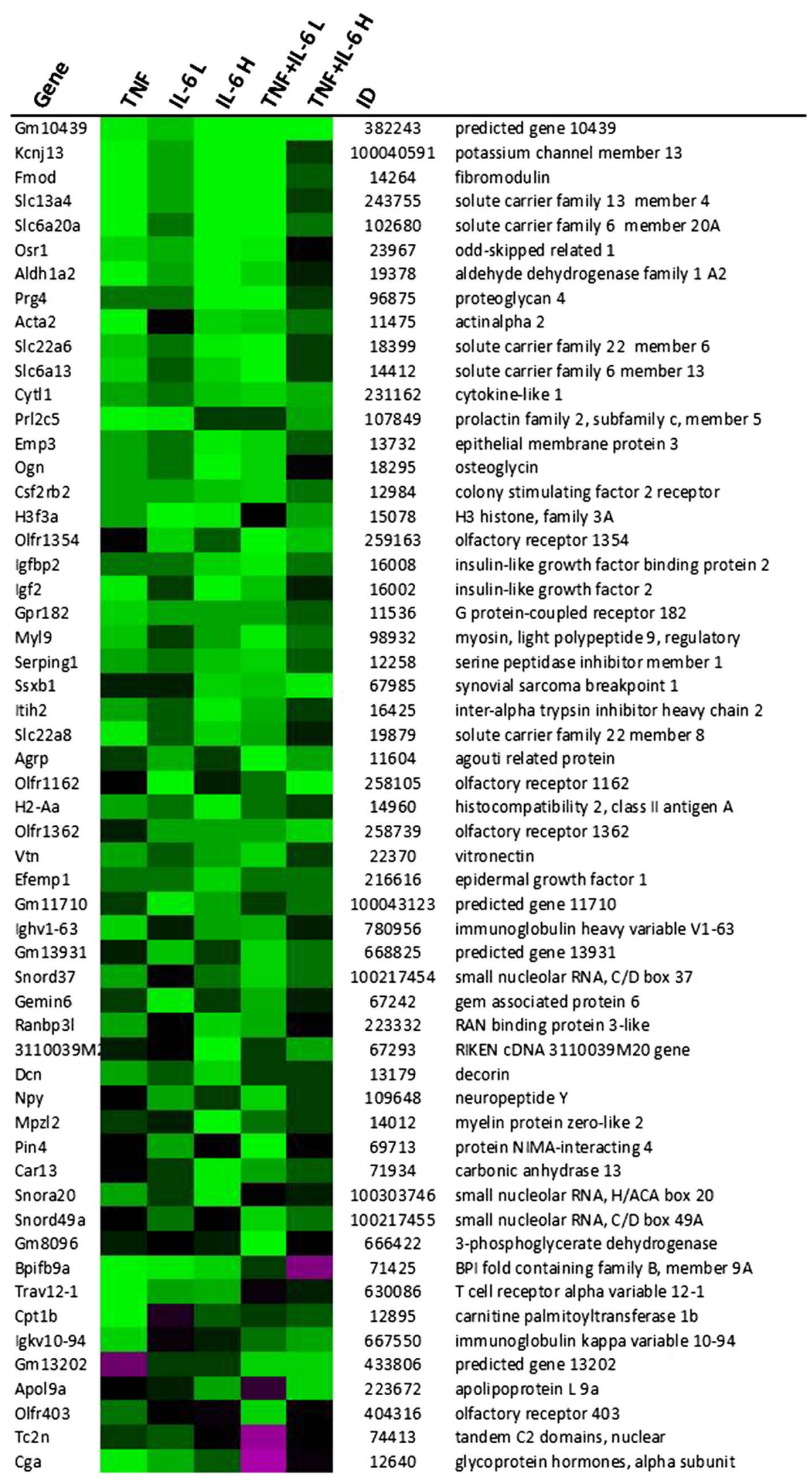


(see figure on previous page.)

Fig. 6 Gene expression changes in hypothalamus after ip injection with TNFa, IL-6 or both. Top upregulated genes and top downregulated genes in treated groups compared to control group. Each row represents a gene and each column represents a group of animals. Magenta colour indicates genes that were higher expressed as control and green colour indicates genes that were lower expressed as the control. Black indicates genes whose expression was similar to compared to control. ID: Entrez ID

before that neurons also express high levels of various cytokines [34] and that synthesis of cytokines occurs in response to blood-borne inflammatory mediators [35]. This suggests that neurons may play a significant role in development and sustainment of hypothalamic inflammation. Furthermore, we showed that this inflammatory response in hypothalamic neurons coincided with elevated serotonin secretion and increased intracellular 5-HIAA levels, reflecting an increase in serotonin turnover. In the mice, injection with combinations of TNF $\alpha$ and IL-6 resulted in increased hypothalamic 5-HIAA levels, while tissue serotonin levels did not differ from controls. A possible explanation for this apparent difference could be that in cell experiments, secreted serotonin was measured. However, in total tissue homogenates, intracellular serotonin cannot be distinguished from serotonin released into the synaptic cleft. Therefore, total tissue homogenate levels of serotonin do not
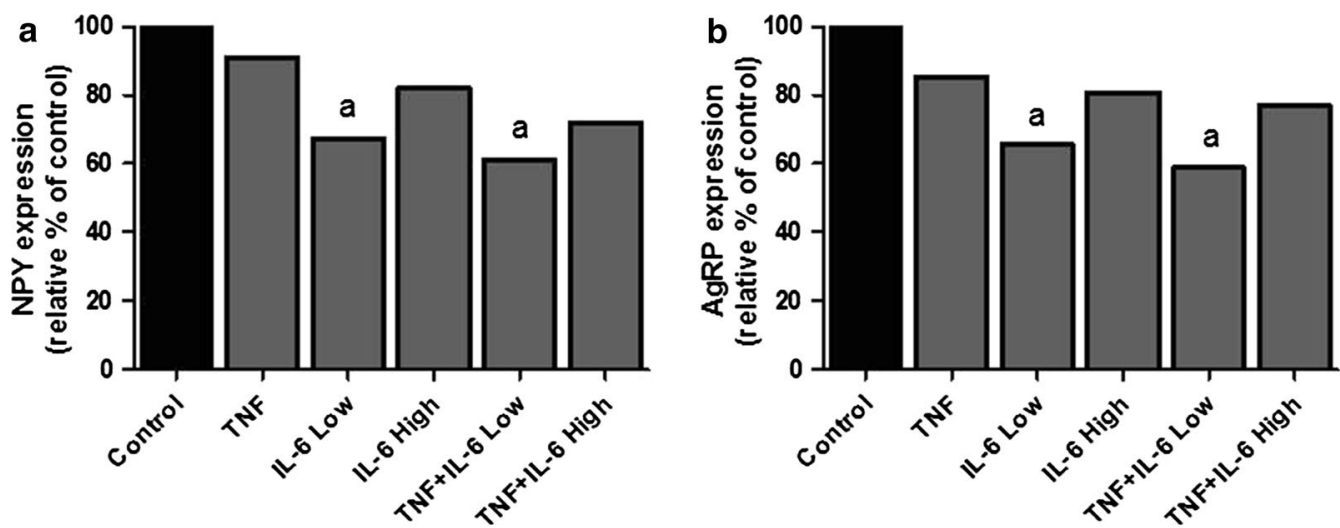

Fig. 7 Gene expression changes in hypothalamus after ip injection with TNFa, IL-6 or both. a, b Relative gene expression compared to control group of NPY and AgRP. a Significantly different from Control group $(P<0.05)$, AgRP agouti related protein, NPY neuropeptide $Y(n=6)$

Table 1 Upstream regulators in hypothalamus after ip injection with TNFa and IL-6

\begin{tabular}{|c|c|c|c|c|c|}
\hline \multicolumn{6}{|l|}{ Upstream regulators } \\
\hline & TNF & IL-6 low & IL-6 high & TNF + IL-6 low & TNF + IL-6 high \\
\hline \multirow[t]{4}{*}{ Cytokines } & & & IFNG & IFNG & \\
\hline & IFNG & IFNG & IL6 & IL6 & \\
\hline & IL6 & IL6 & PRL & PRL & IFNG \\
\hline & TGFB1 & PRL & TGFB1 & TGFB1 & TGFB1 \\
\hline \multirow[t]{4}{*}{ Enzymes } & & & TGFBR1 & TGFBR1 & \\
\hline & & TGFBR1 & IKBKG & IKBKG & \\
\hline & TGFBR1 & IKBKG & $\mathrm{ALDH} 1 \mathrm{~A} 2$ & $\mathrm{ALDH} 1 \mathrm{~A} 2$ & \\
\hline & $\mathrm{ALDH} 1 \mathrm{~A} 2$ & PARP9 & PARP9 & PARP9 & TGFBR1 \\
\hline \multirow[t]{6}{*}{ Transcription factors } & & & SRF & & \\
\hline & & & MKL1 & SRF & \\
\hline & SRF & & SMAD7 & MKL1 & \\
\hline & MKL1 & SMAD7 & CEBPB & CEBPB & SRF \\
\hline & STAT1 & CEBPB & STAT1 & STAT1 & MKL1 \\
\hline & IRF3 & IRF3 & IRF3 & IRF3 & SMAD7 \\
\hline
\end{tabular}


properly reflect its release, which has also been reported for other monoamines and catecholamines [36]. However, 5-HIAA, the stable metabolic end product of 5HT is considered to be a good reflection for serotonin release [37-39] and therefore widely acknowledged as marker for serotonergic activity $[25,26]$.

Levels of 5-HIAA are measured in different matrices, models and diseases, including various forms of depression and aggressive behaviour disorders, where measurement of 5-HIAA gives better results than that of serotonin. Alterations on 5-HIAA are more pronounced and long-lasting, while changes on serotonin can be rapidly diminished [27, 40-42].

In the current experimental setting, $5 \mathrm{HT}$ and metabolites were measured $5 \mathrm{~h}$ after cytokine injection and it could be that alterations of serotonin levels had already diminished by then. A similar reasoning might explain why elevated levels of serotonin's precursor, tryptophan (TRP), were only prominent in mice injected with the combination of the highest dose of IL- 6 and TNF $\alpha$. Tryptophan levels have been reported to rise upon injection with cytokines depending on the type of inflammatory stimulus used. However at the same time, this inflammatory response is associated with increased TRP breakdown by indoleamine 2,3-dioxygenase (IDO), to synthesize kynurenine $[43,44]$.

In plasma, levels of TNF $\alpha$ and IL- 6 were not elevated in the groups treated with a single cytokine. However, when these cytokines were given in combination, high levels of IL-6 and TNF $\alpha$ were measured. It is likely that clearance of the administered cytokines already occurred within $5 \mathrm{~h}$ following injection. For both TNF $\alpha$ and IL-6, complete clearance from the circulation has been reported to occur within $6 \mathrm{~h}$ after ip injection $[45,46]$. Furthermore levels of these cytokines have different temporal profiles, with TNF $\alpha$ plasma being fast responsive and also more rapidly cleared than IL-6 from the blood, but at the same time being more persistent in hypothalamus than IL-6 $[47,48]$.

Food intake showed to decrease in all treated groups and there was no difference between the treatments. It appears that the lowest dose of IL- 6 was sufficient to induce an anorexigenic effect and that higher doses produced no additional anorexigenic activity. This is in line with other reports showing that in contrast to other IL-6 effects, there is no clear dose-dependency of IL-6 when it comes to its activity on food-intake $[49,50]$.

Whole genome gene expression profiles from the hypothalamus and the predicted inflammatory transcriptional regulators showed a high overlap between TNF $\alpha$, IL- 6 and combination groups, indicating that responses of the different treatments were similar. This might be explained by a production of similar cytokines by the host in response to injection with IL-6 or TNFa. In hypothalamic tissue homogenates, increased levels of IL- 6 have been reported after injection with TNF $\alpha$ [51], which suggests that injection with TNF $\alpha$ also leads to activation of IL-6 signalling pathways. The strong down-regulation of expression of two important orexigenic neuropeptide regulators NPY and AgRP also showed to be similar between groups and corresponded to lower food intake in treated groups. This decrease in expression induced by TNF $\alpha$ or IL- 6 supports findings that have been reported in a variety of experimental models including hypothalamic injection with TNF $\alpha$ and genetic overexpression of hypothalamic IL-6 [52, 53].

Gene expression of two genes involved in serotonin signalling, showed to be upregulated in mice treated with TNF $\alpha$ and IL-6. Serotonin has been reported to have an inhibiting action on NPY [13,54,55], suggesting that the increase in serotonergic activity measured in treated mice, might be responsible for the effects on lower NPY expression in these mice.

\section{Conclusions}

In summary, we show that TNF $\alpha$ and IL-6 induce similar inflammatory responses in the hypothalamus and similar effects on food intake. This anorexigenic effect of TNF $\alpha$ and IL- 6 showed to coincidence with increased hypothalamic serotonergic activity, providing further evidence for a role for serotonin in inflammation-induced anorexia.

\section{Methods}

\section{Cell culture and in vitro studies with IL-6, TNFa and LPS}

Murine derived hypothalamic neuronal cell lines hypoE46 and hypoA2/12 (CELLutions Biosystems Inc. Canada) were grown and maintained in DMEM supplemented with $10 \%$ heat-inactivated fetal calf serum, $100 \mathrm{U} / \mathrm{ml}$ penicillin and $100 \mu \mathrm{g} / \mathrm{ml}$ streptomycin at $37{ }^{\circ} \mathrm{C}$ under $5.0 \% \mathrm{CO}_{2}$. Cells were grown in monolayers to $90 \%$ confluency. Then medium was replaced by serum-free DMEM containing penicillin and streptomycin. After $4 \mathrm{~h}$, cells were exposed to LPS $(1 \mu \mathrm{g} / \mathrm{ml})$, TNF $\alpha(100 \mathrm{pg} /$ $\mathrm{ml})$, IL-6 (100 pg/ml) for $24 \mathrm{~h}$, or $\mathrm{KCl}(60 \mathrm{mM})$ for $15 \mathrm{~min}$. After exposure, supernatant was collected to measure levels of serotonin (BAE-5900, LDN, Nordhorn, Germany), IL-6 (DY406, Abingdon, UK), TNFa (DY410, Abingdon, UK) and MCP-1 (DY479, R\&D systems, Abingdon, UK) by enzyme-immuno assay. Cells were homogenized in $40 \mathrm{mM}$ Tris, $1 \mathrm{mM}$ EDTA, $5 \mathrm{mM}$ EGTA and $0.50 \%$ Triton X-100. Homogenates were used to measure 5-hydroxyindoleacetic acid (5-HIAA) by ELISA (MBS261481, MyBiosource, Breda, The Netherlands) and corrected for total protein content (Pierce Bicinchoninic acid Rockford, IL, USA). Cytotoxicity was determined by measuring LDH leakage and cell viability using an XTT 
conversion assay after $48 \mathrm{~h}$ of exposure (Roche Diagnostics, Mannheim, Germany). All experiments were performed three times in quadruplicate.

\section{Animals}

C57BL/6 male mice (Harlan, Horst, The Netherlands), weighing approximately $20 \mathrm{~g}$, were individually housed 1 week before start of the experiment. Mice were maintained on a $12 \mathrm{~h}$ light: $12 \mathrm{~h}$ dark cycle in a climate-controlled room $\left(21 \pm 1{ }^{\circ} \mathrm{C}\right)$. Standard diet was ad libitum available during the entire experiment from one hour prior to dark phase until start of the light phase (Arie Blok B.V., Woerden, and The Netherlands). Water was freely available $24 \mathrm{~h}$ a day. Food intake, water intake and body weight were monitored daily from 1 week prior to the end of the experiment.

All experimental procedures were made in accordance with the European Community guidelines for the use of laboratory animals and complied with the principles of good laboratory animal care.

\section{Experimental set-up}

Mice were injected intraperitoneal (ip) with 50ul of saline vehicle (G-Biosciences, St. Louis, USA), TNFa (Peprotech, London, UK), IL-6 (Peprotech, London, UK), or both TNF $\alpha$ and IL-6. The study included 6 groups: Control, TNF $\alpha$, IL- 6 Low, IL-6 High, TNF $\alpha$ + IL-6 Low and TNF $\alpha$ + IL-6 High (Table 2). The rationale to study different doses and combinations of IL- 6 was based on our previous observations in mouse tumour models and the generally recognized central role of IL- 6 as link between cancer and inflammation [13, 24]. Combinations TNF + IL-6 Low and TNF + IL-6 High reflect plasma levels measured in C26 tumour-bearing mice and Lewis Lung tumour-bearing mice respectively. Each group included 12 mice, of which 6 mice were used for determination of hypothalamic metabolites and 6 mice were used for hypothalamic gene expression analysis. Mice were injected $1 \mathrm{~h}$ prior to the dark phase. Five hours after injection, blood was collected by cardiac puncture under general anaesthesia. After sacrifice, brain, hypothalamus and organs were weighted, frozen in liquid nitrogen and stored at $-80^{\circ} \mathrm{C}$.

Table 2 Experimental groups

\begin{tabular}{lll}
\hline Group & Nr of mice & $\begin{array}{l}\text { Treatment (IP injection } \\
\mathbf{5 0} \boldsymbol{\mu l} \text { sodium chlorine) }\end{array}$ \\
\hline Control & 12 & Sodium chloride $0.9 \%$ \\
TNF & 12 & $15 \mathrm{pg} \mathrm{TNFa}$ \\
IL-6 low & 12 & $50 \mathrm{pg} \mathrm{IL}-6$ \\
IL-6 high & 12 & $800 \mathrm{pg} \mathrm{IL}-6$ \\
TNF + IL-6 low & 12 & $50 \mathrm{pg} \mathrm{IL}-6+15 \mathrm{pg} \mathrm{TNFa}$ \\
TNF + IL-6 high & 12 & $800 \mathrm{pg} \mathrm{IL}-6+15 \mathrm{pg}$ TNFa \\
\hline
\end{tabular}

\section{Hypothalamic metabolites 5-HT, 5-HIAA, DA, DOPAC and TRP}

Hypothalamus tissue was homogenised by sonication in $10 \mu \mathrm{l}$ of $0.5 \mathrm{M}$ perchloric acid per $\mathrm{mg}$ of tissue and stored at $-80{ }^{\circ} \mathrm{C}$ until analysis. Concentrations of DA, 5-HT, DOPAC, 5-HIAA and TRP were determined by HPLC with tandem mass spectrometry (MS/MS) detection, using deuterated internal standards of the analytes. Of each LC-MS sample, an aliquot was injected onto the HPLC column by an automated sample injector (SIL10-20AC-HT, Shimadzu, Japan). Chromatographic separation was performed on a SynergiMax column $(100 \times 3.0 \mathrm{~mm}$, particle size $3 \mu \mathrm{m})$ held at a temperature of $35{ }^{\circ} \mathrm{C}$. The mobile phases consisted of A: ultrapurified $\mathrm{H}_{2} \mathrm{O}+0.1 \%$ formic and B: acetonitrile: ultrapurified $\mathrm{H} 2 \mathrm{O}(75: 25)+0.1 \%$ formic acid. Elution of the compounds proceeded using a suitable linear gradient at a flow rate of $0.3 \mathrm{ml} / \mathrm{min}$. The MS analyses were performed using an API $4000 \mathrm{MS} / \mathrm{MS}$ system consisting of an API $4000 \mathrm{MS} / \mathrm{MS}$ detector and a Turbo Ion Spray interface (Applied Biosystems, the Netherlands). The acquisitions on API 4000 were performed in positive ionization mode for 5-HT, DA and TRP and in negative mode for 5-HIAA and DOPAC, with optimized settings for the analytes. The instrument was operated in multiple-reaction-monitoring (MRM) mode.

Data were calibrated and quantified using the Analyst data system (Applied Biosystems, version 1.6.2, the Netherlands). Concentrations in experimental samples were calculated based on the calibration curve in the corresponding matrix.

\section{Hypothalamic transcriptomics (microarray)}

Total RNA from the hypothalamus was isolated by using RNeasy Lipid tissue kit (Qiagen, Venlo, The Netherlands). RNA concentrations were measured by absorbance at $260 \mathrm{~nm}$ (Nanodrop). RNA quality was checked using the RNA 6000 Nano assay on the Agilent 2100 Bioanalyzer (Agilent Techologies, Amsterdam, The Netherlands) according to the manufacturer's protocol. For each mouse, total RNA (100 ng) was labelled using the Ambion WT expression kit (Life Technologies, Bleiswijk, The Netherlands). Micro-array experiments were performed by using Affymetrix Mouse Gene 1.1 ST arrays. In the TNF $\alpha$ treated group, 1 sample gave multiple spots on the array and was therefore excluded from analysis. Array data were analysed using an in-house, on-line system [56]. Briefly, probesets were redefined according to Dai et al. [57] using remapped CDF version 18.0.1 based on the Entrez Gene database. In total these arrays target 21,266 unique genes. Robust multi-array (RMA) analysis was used to obtain expression values $[58,59]$. We only took genes into account that had an intensity $>20$ on 
at least 3 arrays and at least 7 probes per genes. Genes were considered differentially expressed at $\mathrm{P}<0.05$ after intensity-based moderated t-statistics [60]. Further functional interpretation of the data was performed through the use of IPA (Ingenuity ${ }^{\circledR}$ Systems, www.ingenuity. com). Genes from the data set that met the cut-off of 1.2 fold change and $\mathrm{P}$ value cut-off of 0.05 were considered for the analysis. Upstream regulators were identified by using cut-off values of $\mathrm{z}$-score $>1.96$ and $\mathrm{z}$-score $<-1.96$ combined with $\mathrm{P}<0.05$. Furthermore for this upstream regulators analysis, only endogenous metabolites were considered (chemical drugs and compounds were excluded from analysis). Array data have been submitted to the Gene Expression Omnibus (GEO), accession number GSE69151.

\section{Plasma cytokines and gut hormones}

Plasma levels of TNF- $\alpha$, amylin (Active), C-Peptide 2, ghrelin (Active), GIP (Total), GLP-1 (Active), glucagon, IL-6, insulin, leptin, MCP-1, Pancreatic Peptide (PP), PYY and resistin were measured using the 12-plex Mouse Metabolic Hormone Magnetic bead panel (Merck Millipore, Amsterdam, The Netherlands). Serum amyloid was measured in liver homogenates using SAA mouse ELISA kit (Life technologies, Bleiswijk, The Netherlands).

\section{Statistics}

Data were analysed by statistical analysis of variance (ANOVA) followed by a post hoc Bonferroni test or by a Dunnet test. Differences were considered significant at a two-tailed $\mathrm{P}<0.05$. Statistical analyses were performed using Graphpad Prism 5.

\section{Additional file}

Additional file 1: Figure S1. Plasma levels of gut hormones. Effect of ipinjection with TNFa, IL-6 or both on A) Resistin, B) Peptide YY, C) Glucagon-like peptide (GLP-1), D) MCP-1, E) Insulin, F) C-peptide, G) Gastric inhibitoryprotein (GIP), H) Amylin, I) Leptin.

\begin{abstract}
Abbreviations
5HIAA: 5-hydroxyindoleacetic acid; 5HT: 5-hydroxytryptamine (serotonin); AgRP: agouti related protein; BBB: blood brain barrier; IDO: indoleamine 2,3-dioxygenase (IDO); IL-6: interleukin-6; NPY: neuropeptide Y; POMC: proopiomelanocortin; TNFa: tumor necrosis factor alpha.
\end{abstract}

\section{Authors' contributions}

$\mathrm{JD}, \mathrm{ML}$ and $\mathrm{KN}$ have designed, conducted, analysed and interpreted in vivo animal and in vitro studies. MH has measured and analysed murine hypothalamic metabolites. MB and RW were involved in micro-array analysis of mouse hypothalamus and interpretation of all results. The manuscript contains original unpublished work and is currently not under consideration elsewhere. All authors read and approved the final manuscript.

\section{Author details}

${ }^{1}$ Nutrition and Pharmacology Group, Division of Human Nutrition, Wageningen University, Bomenweg 2,6703HD Wageningen, The Netherlands. ${ }^{2}$ Nutrition, Metabolism and Genomics Group, Division of Human Nutrition,
Wageningen University, Bomenweg 2,6703HD Wageningen, The Netherlands. 3 Brains On-line, P.O. Box 4030, 9701 EA Groningen, The Netherlands.

\section{Acknowledgements}

We would like to thank N. van der Wielen, L. Janssen Duijghuijsen, Y. Wang, S. Keshtkar, S. Rouschop, P. Vinke, L. Strolenberg, W. Blauw and B. Weijers for their technical assistance.

\section{Availability of supporting data}

Array data have been submitted to the Gene Expression Omnibus, Accession Number GSE69151.

\section{Competing interests}

$J \mathrm{D}, \mathrm{RW}, \mathrm{MB}, \mathrm{ML}$, and $\mathrm{MH}$ have nothing to disclose. $\mathrm{KN}$ is a guest employee at Nutricia Research, a medical nutrition company.

\section{Ethical approval animal experiments}

All animal experimental procedures were ethically approved in accordance with the European Community guidelines for the use of laboratory animals and complied with the principles of good laboratory animal care by the Dutch DEC committee reference number 2014038.

\section{Funding}

The research leading to these results has received funding from the European Union's Seventh Framework Programme for research, technological development and demonstration under Grant Agreement No. 266408 (Full4Health).

Received: 3 September 2015 Accepted: 11 May 2016

Published online: 20 May 2016

\section{References}

1. Hopkins SJ, Rothwell NJ. Cytokines and the nervous system. I: expression and recognition. Trends Neurosci. 1995;18(2):83-8.

2. Zhu CB, Lindler KM, Owens AW, Daws LC, Blakely RD, Hewlett WA. Interleukin-1 receptor activation by systemic lipopolysaccharide induces behavioral despair linked to MAPK regulation of CNS serotonin transporters. Neuropsychopharmacology. 2010;35(13):2510-20.

3. Endo M, Masaki T, Seike M, Yoshimatsu H. Involvement of stomach ghrelin and hypothalamic neuropeptides in tumor necrosis factor-alpha-induced hypophagia in mice. Regul Pept. 2007;140(1-2):94-100.

4. Jang PG, Namkoong C, Kang GM, Hur MW, Kim SW, Kim GH, Kang Y, Jeon MJ, Kim EH, Lee MS, Karin M, Baik JH, Park JY, Lee KU, Kim YB, Kim MS. NF-kappaB activation in hypothalamic pro-opiomelanocortin neurons is essential in illness- and leptin-induced anorexia. J Biol Chem. 2010;285(13):9706-15.

5. Gutierrez EG, Banks WA, Kastin AJ. Murine tumor necrosis factor alpha is transported from blood to brain in the mouse. J Neuroimmunol. 1993;47(2):169-76.

6. Banks WA, Kastin AJ, Gutierrez EG. Penetration of interleukin-6 across the murine blood-brain barrier. Neurosci Lett. 1994;179(1-2):53-6.

7. Banks WA, Kastin AJ. Blood to brain transport of interleukin links the immune and central nervous systems. Life Sci. 1991;48(25):PL117-21.

8. Herman AP, Krawczynska A, Bochenek J, Antushevich H, Herman A, Tomaszewska-Zaremba D. Peripheral injection of SB203580 inhibits the inflammatory-dependent synthesis of proinflammatory cytokines in the hypothalamus. Biomed Res Int. 2014;2014:475152.

9. Peruzzo B, Pastor FE, Blazquez JL, Schobitz K, Pelaez B, Amat P, Rodriguez EM. A second look at the barriers of the medial basal hypothalamus. Exp Brain Res. 2000;132(1):10-26.

10. Krisch $\mathrm{B}$, Leonhardt $\mathrm{H}$. The functional and structural border of the neurohemal region of the median eminence. Cell Tissue Res. 1978;192(2):327-39.

11. Rana I, Stebbing M, Kompa A, Kelly DJ, Krum H, Badoer E. Microglia activation in the hypothalamic PVN following myocardial infarction. Brain Res. 2010;1326:96-104.

12. Ronaldson PT, Bendayan R. HIV-1 viral envelope glycoprotein gp120 triggers an inflammatory response in cultured rat astrocytes and regulates the functional expression of P-glycoprotein. Mol Pharmacol. 2006;70(3):1087-98. 
13. Dwarkasing JT, Boekschoten MV, Argilès JM, van Dijk M, Busquets S, Penna F, Toledo M, Laviano A, Witkamp RF, van Norren K. Differences in food intake of tumour-bearing cachectic mice are associated with hypothalamic serotonin signalling. J Cachexia Sarcopenia Muscle. 2015;6(1):84-94.

14. Laviano A, Inui A, Meguid MM, Molfino A, Conte C, Rossi Fanelli F. NPY and brain monoamines in the pathogenesis of cancer anorexia. Nutrition. 2008;24(9):802-5.

15. Meguid MM, Ramos EJ, Laviano A, Varma M, Sato T, Chen C, Qi Y, Das UN. Tumor anorexia: effects on neuropeptide $Y$ and monoamines in paraventricular nucleus. Peptides. 2004;25(2):261-6.

16. Delorme ML, Denis J, Nordlinger B, Boschat M, Opolon P. Relationship between plasma and brain tryptophan in pigs during experimental hepatic coma before and after hemodialysis with selective membranes. J Neurochem. 1981;36(3):1058-66.

17. Dawson R, Oparil S. Genetic and salt-related alterations in monoamine neurotransmitters in Dahl salt-sensitive and salt-resistant rats. Pharmacology. 1986;33(6):322-33

18. Calapai G, Corica F, Corsonello A, Sautebin L, Di Rosa M, Campo GM, Buemi M, Mauro VN, Caputi AP. Leptin increases serotonin turnover by inhibition of brain nitric oxide synthesis. J Clin Invest. 1999;104(7):975-82.

19. Brunetti L, Orlando G, Recinella L, Leone S, Ferrante C, Chiavaroli A, Lazzarin F, Vacca M. Glucagon-like peptide 1 (7-36) amide (GLP-1) and exendin-4 stimulate serotonin release in rat hypothalamus. Peptides. 2008;29(8):1377-81.

20. Nonogaki K, Ohashi-Nozue K, Oka Y. A negative feedback system between brain serotonin systems and plasma active ghrelin levels in mice. Biochem Biophys Res Commun. 2006;341(3):703-7.

21. Xu Y, Jones JE, Kohno D, Williams KW, Lee CE, Choi MJ, Anderson JG, Heisler LK, Zigman JM, Lowell BB, Elmquist JK. 5-HT2CRs expressed by pro-opiomelanocortin neurons regulate energy homeostasis. Neuron 2008;60(4):582-9.

22. Dryden S, Frankish HM, Wang Q, Williams G. Increased feeding and neuropeptide Y (NPY) but not NPY mRNA levels in the hypothalamus of the rat following central administration of the serotonin synthesis inhibitor p-chlorophenylalanine. Brain Res. 1996;724(2):232-7.

23. Cangiano C, Laviano A, Meguid MM, Mulieri M, Conversano L, Preziosa I, Rossi-Fanelli F. Effects of administration of oral branched-chain amino acids on anorexia and caloric intake in cancer patients. J Natl Cancer Inst. 1996;88(8):550-2.

24. Dwarkasing JT, van Dijk M, Dijk FJ, Boekschoten MV, Faber J, Argiles JM, Laviano A, Muller M, Witkamp RF, van Norren K. Hypothalamic food intake regulation in a cancer-cachectic mouse model. J Cachexia Sarcopenia Muscle. 2013:5(2):159-69.

25. Matsumoto M, Togashi H, Yoshioka M, Hirokami M, Tochihara M, Ikeda T, Smith $\mathrm{CB}$, Saito $\mathrm{H}$. Inhibitory effects of clonidine on serotonergic neuronal activity as measured by cerebrospinal fluid serotonin and its metabolite in anesthetized rats. Life Sci. 1993;53(8):615-20.

26. Shannon NJ, Gunnet JW, Moore KE. A comparison of biochemical indices of 5-hydroxytryptaminergic neuronal activity following electrical stimulation of the dorsal raphe nucleus. J Neurochem. 1986;47(3):958-65.

27. Winberg S, Myrberg AA Jr, Nilsson GE. Predator exposure alters brain serotonin metabolism in bicolour damselfish. NeuroReport. 1993;4(4):399-402.

28. Virkkunen M, Linnoila M. Brain serotonin, type II alcoholism and impulsive violence. J Stud Alcohol Suppl. 1993;11:163-9.

29. Dhillon SS, Belsham DD. Leptin differentially regulates NPY secretion in hypothalamic cell lines through distinct intracellular signal transduction pathways. Regul Pept. 2011;167(2-3):192-200.

30. Dhillon SS, Belsham DD. Estrogen inhibits NPY secretion through membrane-associated estrogen receptor (ER)-alpha in clonal, immortalized hypothalamic neurons. Int J Obes (Lond). 2011;35(2):198-207.

31. Arendt BK, Velazquez-Dones A, Tschumper RC, Howell KG, Ansell SM, Witzig TE, Jelinek DF. Interleukin 6 induces monocyte chemoattractant protein-1 expression in myeloma cells. Leukemia. 2002;16(10):2142-7.

32. Kalin S, Heppner FL, Bechmann I, Prinz M, Tschop MH, Yi CX. Hypothalamic innate immune reaction in obesity. Nat Rev Endocrinol. 2015;11:339-51.

33. Thaler JP, Yi CX, Schur EA, Guyenet SJ, Hwang BH, Dietrich MO, Zhao X, Sarruf DA, Izgur V, Maravilla KR, Nguyen HT, Fischer JD, Matsen ME, Wisse
BE, Morton GJ, Horvath TL, Baskin DG, Tschop MH, Schwartz MW. Obesity is associated with hypothalamic injury in rodents and humans. J Clin Invest. 2012;122(1):153-62.

34. Acarin L, Gonzalez B, Castellano B. Neuronal, astroglial and microglial cytokine expression after an excitotoxic lesion in the immature rat brain. Eur J Neurosci. 2000;12(10):3505-20.

35. Shibata M. Hypothalamic neuronal responses to cytokines. Yale J Biol Med. 1990;63(2):147-56

36. Meeusen R, De Meirleir K. Exercise and brain neurotransmission. Sports Med. 1995;20(3):160-88.

37. Meeusen R, Thorre K, Chaouloff F, Sarre S, De Meirleir K, Ebinger G, Michotte Y. Effects of tryptophan and/or acute running on extracellular 5-HT and 5-HIAA levels in the hippocampus of food-deprived rats. Brain Res. 1996;740(1-2):245-52.

38. Blomstrand E, Perrett D, Parry-Billings M, Newsholme EA. Effect of sustained exercise on plasma amino acid concentrations and on 5-hydroxytryptamine metabolism in six different brain regions in the rat. Acta Physiol Scand. 1989:136(3):473-81.

39. Chaouloff F, Laude D, Elghozi JL. PHysical exercise: evidence for differential consequences of tryptophan on 5-HT synthesis and metabolism in central serotonergic cell bodies and terminals. J Neural Transm. 1989;78(2):121-30.

40. Barton DA, Esler MD, Dawood T, Lambert EA, Haikerwal D, Brenchley C, Socratous F, Hastings J, Guo L, Wiesner G, Kaye DM, Bayles R, Schlaich MP, Lambert GW. Elevated brain serotonin turnover in patients with depression: effect of genotype and therapy. Arch Gen Psychiatry. 2008;65(1):38-46.

41. Vermeiren Y, Van Dam D, Aerts T, Engelborghs S, De Deyn PP. Monoaminergic neurotransmitter alterations in postmortem brain regions of depressed and aggressive patients with Alzheimer's disease. Neurobiol Aging. 2014;35(12):2691-700.

42. Vermeiren Y, Van Dam D, Aerts T, Engelborghs S, De Deyn PP. Brain regionspecific monoaminergic correlates of neuropsychiatric symptoms in Alzheimer's disease. J Alzheimers Dis. 2014;41(3):819-33.

43. Dinel AL, Andre C, Aubert A, Ferreira G, Laye S, Castanon N. Lipopolysaccharide-induced brain activation of the indoleamine 2,3-dioxygenase and depressive-like behavior are impaired in a mouse model of metabolic syndrome. Psychoneuroendocrinology. 2014;40:48-59.

44. Sato T, Laviano A, Meguid MM, Chen C, Rossi-Fanelli F, Hatakeyama K. Involvement of plasma leptin, insulin and free tryptophan in cytokineinduced anorexia. Clin Nutr. 2003;22(2):139-46.

45. Dunn AJ. Stress-related changes in cerebral catecholamine and indoleamine metabolism: lack of effect of adrenalectomy and corticosterone. J Neurochem. 1988;51(2):406-12

46. Xiang B, Zhang G, Guo L, Li XA, Morris AJ, Daugherty A, Whiteheart SW, Smyth SS, Li Z. Platelets protect from septic shock by inhibiting macrophage-dependent inflammation via the cyclooxygenase 1 signalling pathway. Nat Commun. 2013;4:2657.

47. Kim YW, Kim KH, Ahn DK, Kim HS, Kim JY, Lee DC, Park SY. Time-course changes of hormones and cytokines by lipopolysaccharide and its relation with anorexia. J Physiol Sci. 2007;57(3):159-65.

48. Kakizaki Y, Watanobe H, Kohsaka A, Suda T. Temporal profiles of interleukin-1 beta, interleukin-6, and tumor necrosis factor-alpha in the plasma and hypothalamic paraventricular nucleus after intravenous or intraperitoneal administration of lipopolysaccharide in the rat: estimation by push-pull perfusion. Endocr J. 1999;46(4):487-96.

49. Schobitz B, Pezeshki G, Pohl T, Hemmann U, Heinrich PC, Holsboer F, Reul JM. Soluble interleukin-6 (IL-6) receptor augments central effects of IL-6 in vivo. FASEB J. 1995:9(8):659-64.

50. Wang J, Leibowitz KL. Central insulin inhibits hypothalamic galanin and neuropeptide $Y$ gene expression and peptide release in intact rats. Brain Res. 1997:777(1-2):231-6.

51. Amaral ME, Barbuio R, Milanski M, Romanatto T, Barbosa HC, Nadruz W, Bertolo MB, Boschero AC, Saad MJ, Franchini KG, Velloso LA. Tumor necrosis factor-alpha activates signal transduction in hypothalamus and modulates the expression of pro-inflammatory proteins and orexigenic/ anorexigenic neurotransmitters. J Neurochem. 2006;98(1):203-12.

52. Arruda AP, Milanski M, Romanatto T, Solon C, Coope A, Alberici LC, Festuccia WT, Hirabara SM, Ropelle E, Curi R, Carvalheira JB, Vercesi AE, Velloso LA. Hypothalamic actions of tumor necrosis factor alpha provide the 
thermogenic core for the wastage syndrome in cachexia. Endocrinology. 2010;151(2):683-94

53. Senaris RM, Trujillo ML, Navia B, Comes G, Ferrer B, Giralt M, Hidalgo J. Interleukin-6 regulates the expression of hypothalamic neuropeptides involved in body weight in a gender-dependent way. J Neuroendocrinol. 2011;23(8):675-86.

54. Shinozaki T, Kimura M, Hosoyamada M, Shibasaki T. Fluvoxamine inhibits weight gain and food intake in food restricted hyperphagic Wistar rats. Biol Pharm Bull. 2008;31(12):2250-4.

55. Dryden S, Frankish HM, Wang Q, Pickavance L, Williams G. The serotonergic agent fluoxetine reduces neuropeptide $Y$ levels and neuropeptide $Y$ secretion in the hypothalamus of lean and obese rats. Neuroscience. 1996;72(2):557-66.

56. Lin K, Kools H, de Groot PJ, Gavai AK, Basnet RK, Cheng F, Wu J, Wang X, Lommen A, Hooiveld GJ, Bonnema G, Visser RG, Muller MR, Leunissen JA. MADMAX — management and analysis database for multiple omics experiments. J Integr Bioinform. 2011;8(2):160.
57. Dai M, Wang P, Boyd AD, Kostov G, Athey B, Jones EG, Bunney WE, Myers RM, Speed TP, Akil H, Watson SJ, Meng F. Evolving gene/transcript definitions significantly alter the interpretation of GeneChip data. Nucleic Acids Res. 2005;33(20):e175.

58. Irizarry RA, Bolstad BM, Collin F, Cope LM, Hobbs B, Speed TP. Summaries of Affymetrix GeneChip probe level data. Nucleic Acids Res. 2003;31(4):e15.

59. Bolstad BM, Irizarry RA, Astrand M, Speed TP. A comparison of normalization methods for high density oligonucleotide array data based on variance and bias. Bioinformatics. 2003;19(2):185-93.

60. Sartor MA, Tomlinson CR, Wesselkamper SC, Sivaganesan S, Leikauf GD, Medvedovic M. Intensity-based hierarchical Bayes method improves testing for differentially expressed genes in microarray experiments. BMC Bioinformatics. 2006;7:538. 